\title{
Effectiveness of Isosorbide Mononitrate in Cervical Ripening before Induction of Labor in Full-term Antenatal Patients
}

\author{
Mohit Agrawal $^{1}$, Neema Acharya ${ }^{2}$, Ketav Joshi $^{3}$, Deepti Shrivastava ${ }^{4}$
}

\begin{abstract}
Aim: The aim of the present study is to prove the efficacy of isosorbide mononitrate (IMN) as a cervical ripening agent before induction of labor in term pregnancies.

Materials and methods: The present study was prospective and comparative, experimental randomized placebo-controlled, double-blind study conducted in the Department of Obstetrics and Gynaecology at Acharya Vinoba Bhave Rural Hospital, Sawangi (Meghe), Wardha, over a period of two years extending from September 2014 to August 2016.

Results: There was a marked improvement in Bishop's score in study group as compared to control group. The mean baseline Bishop's score in case group was $2.65+1.29$ and $2.64+1.26$ in control group. Bishop's score after the 1 st dose (i.e., 24 hours after admission) in study group was $5.95+1.56$ and $3.43+1.35$ in control group; $p$ value is 0.001 which was statistically significant while Bishop's score after the 2 nd dose (i.e., 24 hours after the second dose and 48 hours after admission) in study group was $7.73+2.26$ and $4.47+1.73$ in control group.

Conclusion: Isosorbide mononitrate is effective and safe when used for cervical ripening before induction of labor at term without causing any side effect on maternal hemodynamic and hyperstimulation of uterus.

Keywords: Bishop score, IMN, Induction of Labor.

Journal of South Asian Federation of Obstetrics and Gynaecology (2019): 10.5005/jp-journals-10006-1668
\end{abstract}

\section{INTRODUCTION}

Induction of labor is the oldest procedure in obstetrics. Reports suggest that induction of labor dates back to ancient Greece. In modern obstetrics, induction of labor is an intervention designed to artificially start the process of cervical effacement, uterine contractions, and cervical dilatation, eventually leading to the birth of the baby. Induction of labor can be done for maternal or foetal indications, or for both. Clinical indications are hypertensive disorders, postterm pregnancy, premature rupture of membranes, and intrauterine growth retardation of the foetus. Over a period of time, incidence of labor induction for shortening the duration of labor has continued to rise. ${ }^{1}$ It is believed that induction of labor, especially in women with unfavorable cervix, is associated with more failure rate and more complications as compared with spontaneous labor. The rationale behind this is that the uterus during induction is more likely that labor dystocia occurs.

Most of the studied cervical ripening agents commonly used for cervical ripening stimulate uterine contractions which may also lead to fetal distress and increase in operative intervention. Uterine contractions and fetal heart rate (FHR) need to be closely monitored once these agents are administered.

A perfect agent for cervical ripening should improve cervical score without having any effect on uterine contractions.

Nitric oxide induces cervical ripening by changing structural agreement of the cervical collagen and ground substance leading to softening of cervix and does not have significant effect on uterine contraction, thus the use of nitric oxide donor will obviate the need of fetal monitoring and can be safely used for cervical ripening before induction of labor.

Isosorbide mononitrate is a nitric oxide donor and documented as a cervical ripening agent but still not used commonly. We did this
${ }^{1-4}$ Department of Obstetrics and Gynaecology, JNMC, Sawangi, Wardha, Maharashtra, India

Corresponding Author: Neema Acharya, Department of Obstetrics and Gynaecology, JNMC, Sawangi, Wardha, Maharashtra, India, Phone: +91 9326692511, e-mail: neemasacharya@gmail.com

How to cite this article: Agrawal M, Acharya N, et al. Effectiveness of Isosorbide Mononitrate in Cervical Ripening before Induction of Labor in Full-term Antenatal Patients. J South Asian Feder Obst Gynae 2019;11(2):96-99.

Source of support: Nil

Conflict of interest: None

study to evaluate the efficacy and safety of isosrbide mononitrate in preinduction cervical ripening.

\section{Materials and Methods}

The present study was prospective and comparative, experimental randomized placebo-controlled, double-blind study conducted in the Department of Obstetrics and Gynaecology at Acharya Vinoba Bhave Rural Hospital, Sawangi (Meghe), Wardha, over a period of two years extending from September 2014 to August 2016. The study was approved by the ethical committee of Datta Meghe University of Medical Sciences. This was an experimental randomized placebo-controlled, double-blind, study on 200 pregnant women with full-term pregnancy attending antenatal clinic.

Written informed consent was taken from all participants prior to the study. Study sampleincludes a total of 200, including 100 patients in study group and 100 patients in control group.

- Case group: consisted of 100 patients who received IMN

- Control group: consisted of 100 patient who received placebo

(c) The Author(s). 2019 Open Access This article is distributed under the terms of the Creative Commons Attribution 4.0 International License (https://creativecommons. org/licenses/by-nc/4.0/), which permits unrestricted use, distribution, and non-commercial reproduction in any medium, provided you give appropriate credit to the original author(s) and the source, provide a link to the Creative Commons license, and indicate if changes were made. The Creative Commons Public Domain Dedication waiver (http://creativecommons.org/publicdomain/zero/1.0/) applies to the data made available in this article, unless otherwise stated. 


\section{Inclusion Criteria}

These include patients who gave consent for the study with singleton pregnancy, gestational age equal to or more than 37 completed weeks, and poor cervical score $(<6)$.

\section{Exclusion Criteria}

These include patients who refused to give consent for the study, multiple pregnancies, any obstetric cause in which induction of labor is contraindicated (malpresentations, placenta previa, previous scar on uterus, and any coagulation failure), and patients who had other associated medical condition or disease which dose not allow the use of IMN and high-risk pregnancies.

The study population was selected who fulfilled the inclusion criteria after excluding the exclusion criteria. All patients were kept inward till the completion of study. Participants were categorised according to gravida status, i.e., primigravida and multigravida; these were further divided into predefined subgroup according to Bishop's score.

\section{Randomization}

Randomization to IMN and placebo was done in 1:1 ratio by using a table of random numbers generated by Microsoft Excel. Tablets of IMN and placebo were put into 200 individual sealed numbered envelops. After allocation of patient to a particular group, patient received either IMN (40 mg) or placebo (folic acid) through sealed numbered envelop so that researchers and participants were not aware of the allocated treatment until the completion of treatment.

\section{Intervention}

All women in both the group were examined during admission by the unit in-charge. Their demographic, medical, and detailed obstetric history were taken. Physical examination was performed and Bishop's score was measured. Fetal well-being was assessed by antenatal ultrasound and nonstress test (NST) at the time of admission. Patients received tablets from envelop assigned to them and was instilled in the posterior fornix of the vagina under all aseptic precautions.

Patients were reassessed for progress in Bishop's score after 24 hours by the unit in-charge. The change in Bishop's score and other parameters were noted as per proforma. All participants received second dose after 24 hours except those who went into labor.

After the 2 nd dose, patients were reassessed after 24 hours, i.e., 48 hours after the admission. Patients in whom labor was initiated were shifted to labor room and monitored until delivery.

Maternal hemodynamic parameters and side effects along with FHR pattern were monitored during the study.

If the labor did not start 48 hours after the first administration of the drug, labor induction was performed using oxytocin, in physiological dose by titration method started with 5 IU in 500 Ringer's solution starting at 4 milli international units/minutes.

\section{Outcome Measures}

The primary outcome measure included changes in the Bishop's score.

The duration of induction to active phase of labor, duration of induction to delivery interval, maternal complications, newborn's APGAR scores at the 1st and 5th minutes after birth, and cesarean section rates were recorded as secondary outcomes.

\section{Statistical Analysis}

Statistical analysis was performed by using descriptive and inferential statistics with the help of Chi-square test and Student's unpaired t test. The software used in the analysis was IBM SPSS 22.0 and GraphPad Prism 6.0 version and $p<0.05$ is considered as level of significance $(p<0.05)$

\section{Results}

\section{Discussion}

As shown in Table 1 and Figure 1, in the present study, the mean age of women was $21.29 \pm 7.04$ years in case group and $21.71 \pm$ 7.33 years in control group and the mean gestational age was $39.3 \pm 0.89$ weeks ( 275 days) in case group and $39.49 \pm 0.93$ weeks (277 days) in control group.

In our study, there was no significant effect of IMN on materna heart rate and the maternal blood pressure was noted. This finding of our study is in agreement with the study done by Nicoll et al. ${ }^{2}$

In our study, the mean Bishop's score at the time of hospitalization was $2.65 \pm 1.29$ in case group and $2.64 \pm 1.26$ in control group. As shown in Table 2, after 24 hours of admission (i.e., 24 hours after the first dose of IMN and placebo), reassessment of Bishop's score was done, in case group it was $5.95 \pm 1.59$ and in control group it was $3.48 \pm 1.35 ; p$ value was 0.001 which is statistically significant. This result is in agreement with the study done by Elmahdy et al., ${ }^{3}$ Agarwal et al., ${ }^{4}$ Rameez et al. ${ }^{5}$ and Meena et al. ${ }^{6}$ Similarly, Bishop's score was reassessed after 48 hours of admission (i.e., 24 hours after the 2 nd dose of IMN and placebo). In case group it was $7.73 \pm 2.26$ while in control group it was $4.47 \pm 1.73$ as shown in Table 2 and Figure 2; $p$ value was 0.001 which is statistically significant as shown in Table 1. Of 100 patients in case group III, women delivered after the 1st dose of IMN. This result was in agreement with the study done by Alani et al., ${ }^{7}$ Bollapragada et al., ${ }^{8}$ and Habib et al. ${ }^{9}$

In case group, 57 (57\%) were primigravida and 43 (43\%) were multigravida, and in control group, $58 \%$ were primigravida and $42 \%$ were multigravida. The mean Bishop's score at the time of hospitalization in 57 primigravida patients in case group was $1.80 \pm 0.74$ and $1.81 \pm 0.73$ in 58 primigravida patients of control group which was improved to $5.15 \pm 1.22$ and $2.62 \pm 0.91$ in these primigravida patients of case and control group, respectively, after 24 hours of admission. This improvement in mean Bishop's score in primigravida patients at 24 hours is statistically significant as $p$ value was 0.001 . Similarly after 48 hours, Bishop's score improved in primigravida patients of case group to $7.35 \pm 1.73$ and $3.63 \pm$ 1.11 in primigravida patients of control group. $p$ value was 0.001 which is statistically significant. As shown in Table 3 and Fig. 3, the mean Bishop's score at the time of hospitalization in 42 multigravida patients of case group was $3.76 \pm 0.97$ while it was $3.78 \pm 0.89$ in 43 multigravida patients of control group. After 24 hours, the mean Bishop's score improved to $7.00 \pm 1.34$ in these multigravida patients of case group and to $4.54 \pm 1.04$ in multigravida patients of control group. The above-mentioned improvement in mean Bishop's score in multigravida patients at 24 hours was statistically significant as $p$ value was 0.001 . Similarly after 48 hours, the mean Bishop's score in multigravida patients of case group improved to $8.23 \pm 2.76$ and to $5.61 \pm 1.76$ in multigravida patient of control group. This improvement in case group was significant as compared to control group as $p$ value was 0.001 as shown in Table 4 and Figure 4. As described above in the present study at 24 hours after the 1st dose of IMN, there was a marked improvement in the mean Bishop's score in multigravida patients (from $3.76+0.97$ to $7.00+1.34$ ) as compared to primigravida patients of case group (from $1.80+0.74$ to $5.15+1.22$ ). This suggests that multigravida patient can have 
Effectiveness of Isosorbide Mononitrate in Cervical Ripening before Induction of Labor in Full-term Antenatal Patients

Table 1: Demography

\begin{tabular}{lll}
\hline & Case & Control \\
\cline { 2 - 3 } Parameter & $(100)$ & $(n=100)$ \\
\hline Mean age & 21.29 & 21.71 \\
Mean gestational age & 39.35 & 39.49 \\
Primigravida & 57 & 58 \\
Multigravida & 43 & 42 \\
\hline
\end{tabular}

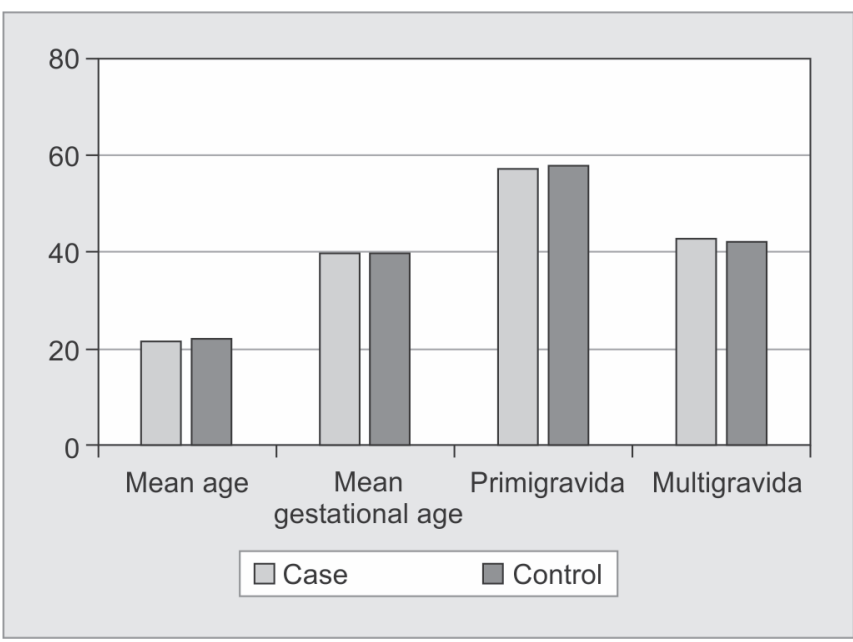

Fig. 1: Demography

Table 2: Bishop's score in case and control group at admission, after 24 hours and after 48 hours admission

\begin{tabular}{lll}
\hline & Case & Control \\
\cline { 2 - 3 } BS & $(n=100)$ & $(n=100)$ \\
\hline At admission & 2.65 & 2.65 \\
After 24 hours & 5.95 & 3.43 \\
After 48 hours & 7.73 & 4.47 \\
\hline
\end{tabular}

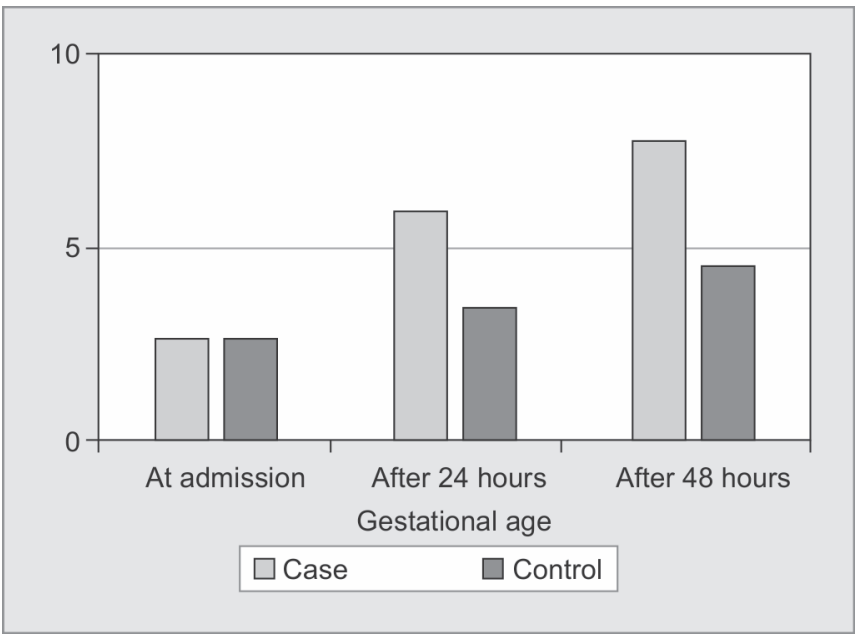

Fig. 2: Bishop's score in case and control group at admission, after 24 hours and after 48 hours admission

inducible cervical score with single dose of IMN. This difference in primigravida and multigravida was not studied in studies done by other researchers, suggesting that further research is needed for dose calibration of IMN according to parity status.
Table 3: Bishop's score in primigravida patients of case and control group at admission, after 24 hours and after 48 hours admission

\begin{tabular}{lll}
\hline & Case & Control \\
\cline { 2 - 3 } BS in primigravida & $(n=57)$ & $(n=58)$ \\
\hline At admission & 1.8 & 1.81 \\
After 24 hours & 5.15 & 2.62 \\
After 48 hours & 7.35 & 3.63 \\
\hline
\end{tabular}

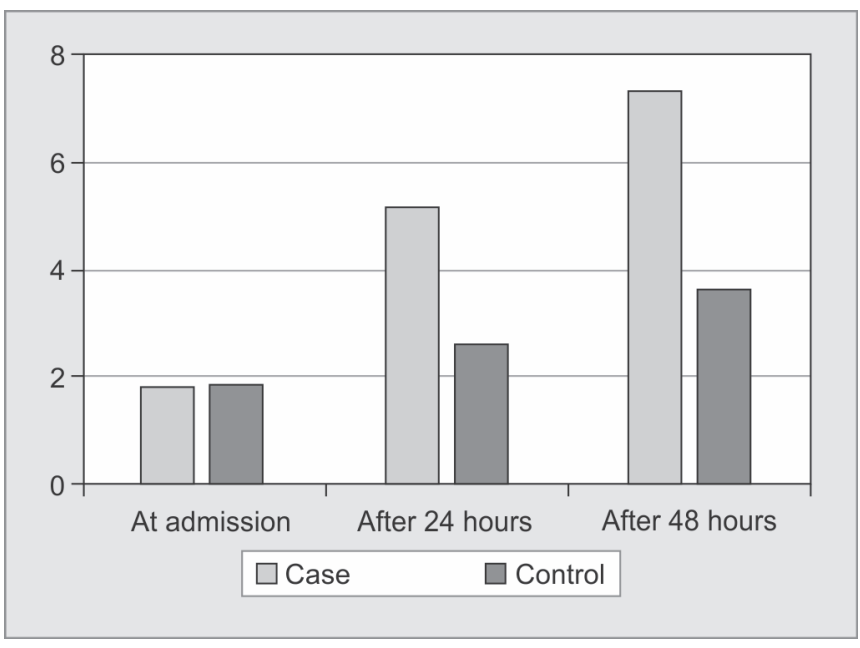

Fig. 3: Bishop's score in primigravida patients of case and control group at admission, after 24 hours and after 48 hours admission

Table 4: Bishop's score in multigravida patients of case and control group at admission, after 24 hours and after 48 hours admission

\begin{tabular}{lll}
\hline & Case & Control \\
\cline { 2 - 3 } BS in multigravida & $(n=43)$ & $(n=42)$ \\
\hline At admission & 3.76 & 3.78 \\
After 24 hours & 7 & 4.54 \\
After 48 hours & 8.23 & 5.61 \\
\hline
\end{tabular}

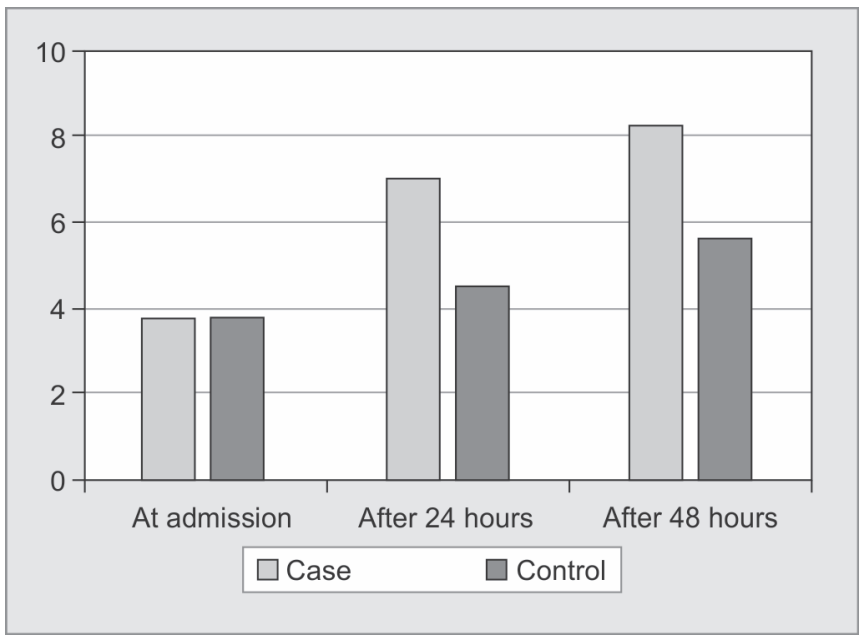

Fig. 4: Bishop's score in multigravida patients of case and control group at admission, after 24 hours and after 48 hours admission

In the present study, none of the patients had uterine hyperstimulation. There was no significant change in the FHR after IMN administration was observed. The mean FHR before IMN was $137 \pm 6.2$ and after IMN was $138 \pm 4.7$ ( $p=0.7$ not significant). This 
result is in agreement with the study done by Habib et al., ${ }^{9}$ Osman et al., ${ }^{10}$ and Thaler et al. ${ }^{11}$

In our study, the mean duration of induction to the active phase of labor in study group with good Bishop's score of $7.73 \pm 2.26$ was 3.36 hours. Whereas in control group with poor Bishop's score of $4.47 \pm 1.73$, the duration was 7.24 hours with $p$ value of 0.001 which was statically significant. Similarly, mean duration of induction to delivery time in case group was 8.6 hours while in control group it was 13.7 hours. This result agrees with the study done by Habib et al. ${ }^{9}$ and Yazdizadeh et al. ${ }^{12}$ In the present study, the cesarean delivery rates were significantly different in case group (10\%) and control group (32\%) but instrumental delivery rates were not significantly different between both the groups. Two patients in case group and 3 patient in control group were delivered by instrumental delivery and indication being maternal exhaustion. This result is in agreement with the study conducted by Calder et al., ${ }^{13}$ Davis et al., ${ }^{14}$ and Vrouenraets FP. ${ }^{15}$

In our study, the main side effect found in study group was headache experienced by $28 \%$ cases. This result is in agreement with the study done by Dave et al. ${ }^{4}$ In their study they found that the main side effect was headache which was experienced by $20 \%$ cases. This result is also in agreement with the study done by Thomson et al. ${ }^{16}$ and Ekerhovd et al. ${ }^{17}$

Isosorbide mononitrate seems to be a safe and effective agent for cervical ripening before induction of labor. It does not have significant effect on maternal hemodynamics and does not cause uterine hyperstimulation during cervical ripening. It also has no effect on FHR.

\section{Conclusion}

- Isosorbide mononitrate improves preinduction cervical ripening score when administered vaginally in two doses of $40 \mathrm{mg}$ each administered 24 hours apart as compared to placebo.

- It does not have significant effect on maternal haemodynamic.

- At 48-hours assessment, a significant improvement in cervical score was observed in both primigravida and multigravida patients but at 24 hours a majority of multigravida patients had inducible cervical score suggesting that they may require single dose.

- By improving the cervical score, its use in cervical ripening before induction of labor reduced both duration of induction to the active phase of labor and induction to delivery time.

- It does not cause uterine hyperstimulation during cervical ripening.

- Isosorbide mononitrate seems to be a safe and effective agent for preinduction cervical ripening.

\section{Clinical Significance}

Isosorbide mononitrate can be used as a preinduction cervical ripening agent and on out patient department (OPD) basis.

\section{References}

1. Declercq ER, Sakala C, et al. Listening to mothers II. Report of the Second National US Survey of Women's Childbearing Experiences. New York, NY: Childbirth Connection; 2006.
2. Nicoll $A E$, Mackenzie $F$, et al. Vaginal application of the nitric oxide donor isosorbide mononitrate for preinduction cervical ripening: a randomized controlled trial to determine effects on maternal and fetal hemodynamics. Am J Obstet Gynecol 2001 Apr;184(5):958-964. DOI: $10.1067 / \mathrm{mob} .2001 .111797$.

3. Elmahdy M, Galal H, et al. Use of Nitric Oxide Donor Isosorbide Mononitrate for Cervical Ripening at 41 Weeks' Gestation. Open J Obstet Gynecol 2016;6(8):451-456. DOI: 10.4236/ojog.2016.68060.

4. Agarwal K, Batra A, et al. Evaluation of isosorbide mononitrate for cervical ripening prior to induction of labor for postdated pregnancy in an outpatient setting. Int J Gynaecol Obstet Off Organ Int Fed Gynaecol Obstet 2012 Sep;118(3):205-209. DOI: 10.1016/ j.ijgo.2012.04.017.

5. Rameez MFM, Goonewardene IMR. Nitric oxide donor isosorbide mononitrate for pre-induction cervical ripening at 41 weeks' gestation: a randomized controlled trial. J Obstet Gynaecol Res 2007 Aug 1;33(4):452-456. DOI: 10.1111/j.1447-0756.2007.00573.x.

6. Meena N, Bindal N, et al. Evaluation of isosorbide mononitrate for cervical ripening prior to induction of labor at term pregnancy in an outpatient setting. Int J Reprod Contracept Obstet Gynecol 2016; 793-797. DOI: 10.18203/2320-1770.ijrcog20160586.

7. Alani H, Nasir SK, et al. A Randomized Clinical Trial of PreInduction Cervical Ripening by Isosorbide Mononitrate at Term Prgnancy. 2016 Oct 8. Available from: http://zjms-hmu.org/files/ articles/210211023154.pdf.

8. Bollapragada SS, MacKenzie F, et al. Randomised placebo-controlled trial of outpatient (at home) cervical ripening with isosorbide mononitrate (IMN) prior to induction of labour-clinical trial with analyses of efficacy and acceptability. The IMOP study. BJOG Int J Obstet Gynaecol 2009 Aug;116(9):1185-1195. DOI: 10.1111/j.14710528.2009.02216.x.

9. Habib SM, Emam SS, et al. Outpatient cervical ripening with nitric oxide donor isosorbide mononitrate prior to induction of labor. Int J Gynaecol Obstet Off Organ Int Fed Gynaecol Obstet 2008 Apr;101(1):57-61. DOI: 10.1016/j.ijgo.2007.09.027.

10. Osman I, MacKenzie F, et al. The "PRIM" study: a randomized comparison of prostaglandin E2 gel with the nitric oxide donor isosorbide mononitrate for cervical ripening before the induction of labor at term. Am J Obstet Gynecol 2006 Apr;194(4):1012-1021. DOI: 10.1016/j.ajog.2005.10.812.

11. Thaler I, Kahana H. The effect of a nitric oxide donor on fetal heart rate patterns in patients with hypertension. Obstet Gynecol 2002 Nov;100(5 Pt 1):987-991. DOI: 10.1016/S0029-7844(02)02277-9.

12. Yazdizadeh $\mathrm{H}$, Abedi $\mathrm{P}$, et al. The impact of isosorbide mononitrate on cervical ripening and labor induction in primiparous women with term pregnancy: a double-blind, randomized, controlled trial. Iran J Nurs Midwifery Res 2013;18(3):246-250.

13. Calder AA, Embrey MP, et al. Ripening of the cervix with extraamniotic PGE2 in viscous gel before induction of labour. Br J Obstet Gynaecol 1977;84:264-268. DOI: 10.1111/j.1471-0528.1977.tb12574.x.

14. Johnson DP, Davis NR, et al. Risk of cesarean delivery after induction at term in nulliparous women with an unfavorable cervix. Am J Obstet Gynecol 2003 Jun 1;188(6):1565-1572. DOI: 10.1067/mob.2003.458.

15. Vrouenraets FP, Roumen FJ, et al. Bishop score and risk of cesarean delivery after induction of labor in nulliparous women. Obstet Gynecol 2005 Apr;105(4):690-697. DOI: 10.1097/01.AOG.0000152338.76759.38.

16. Thomson AJ, Lunan CB, et al. Randomised trial of nitric oxide donor versus prostaglandin for cervical ripening before first-trimester termination of pregnancy. The Lancet 1998 Oct;352(9134):1093-1096. DOI: 10.1016/S0140-6736(98)01289-6.

17. Ekerhovd $E$, Bullarbo $M$, et al. Vaginal administration of the nitric oxide donor isosorbide mononitrate for cervical ripening at term: a randomized controlled study. Am J Obstet Gynecol 2003 Dec 1; 189(6):1692-1697. DOI: 10.1016/S0002-9378(03)00865-2. 